\title{
Nitric oxide and prostacyclin as test agents of vasoreactivity in severe precapillary pulmonary hypertension: predictive ability and consequences on haemodynamics and gas exchange
}

\author{
Philippe Jolliet, Pierre Bulpa, Jean-Benoît Thorens, Marc Ritz, Jean-Claude Chevrolet
}

\begin{abstract}
Background - In patients with primary pulmonary hypertension who respond to vasodilators acutely, survival can be improved by the long term use of calcium channel blockers. However, testing for such a response with calcium channel blockers or prostacyclin $\left(\mathbf{P G I}_{2}\right)$ may cause hypotension and adversely affect gas exchange. Nitric oxide (NO), which does not have these effects, could be a better test agent.

Methods - NO (10, 20, and $40 \mathrm{ppm}$ for 15 minutes), $\mathrm{PGI}_{2}$ (1->10 $\left.\mathrm{ng} / \mathrm{kg} / \mathrm{min}\right)$, and oral nifedipine $(10 \mathrm{mg}$, then $20 \mathrm{mg} / \mathrm{h}$ ) were administered sequentially to 10 patients after determination of the 24 hour spontaneous variability of their pulmonary and systemic mean arterial pressures. Patients were considered responders if the mean pulmonary artery pressure or pulmonary vascular resistance decreased by $20 \%$ or more.
\end{abstract}

Results - Six patients $(60 \%)$ responded to all three agents, and three to none of the agents. One patient responded to $\mathbf{P G I}_{2}$ only. In those who responded to vasodilators, NO had no major effect on gas exchange or systemic haemodynamics, while $\mathrm{PGI}_{2}$ and nifedipine both induced systemic hypotension (mean (SD) systemic arterial pressure 72 (14) versus 89 (19) $\mathrm{mm} \mathrm{Hg}$ with $\mathrm{PGI}_{2}$ and 72 (15) versus 86 (17) $\mathrm{mm} \mathrm{Hg}$ with nifedipine, $\mathrm{p}<0.05$ ) and hypoxaemia $\left(\mathrm{PaO}_{2} 8.7\right.$ (1.4) versus 10.8 (1.0) $\mathrm{kPa}$ with $\mathrm{PGI}_{2}$ and 8.6 (1.4) versus $10.2(1.5) \mathrm{kPa}$ with nifedipine, $\mathrm{p}<0.05)$ and increased venous admixture $(28$ (9) versus $14(4) \%$ with PGI $_{2}$ and 22 (9) versus 13 (5)\% with nifedipine, $\mathbf{p}<0.05$ ).

Conclusions - NO inhalation can accurately predict a vasodilator response to nifedipine in patients with severe pulmonary hypertension without adverse effects on systemic haemodynamics and gas exchange. This absence of side effects may make it a more appropriate agent for testing the vasodilator response.

(Thorax 1997;52:369-372)

Keywords: pulmonary hypertension, vasodilators, nitric oxide, prostacyclin, calcium channel blockers.

In patients with primary pulmonary hypertension an improvement in survival can be obtained by the long term administration of calcium channel blockers to those who respond to vasodilators given acutely. ${ }^{1}$ Calcium channel blockers have been used for this test procedure, but their effect on systemic haemodynamics can induce severe or even life threatening effects. ${ }^{2}$ Because of its short half life and pulmonary vasodilator effect, prostacyclin $\left(\mathrm{PGI}_{2}\right)$ has been administered instead and is regarded as the screening agent of choice. ${ }^{3}$ However, $\mathrm{PGI}_{2}$ is an equally potent systemic vasodilator and may impair pulmonary hypoxic vasoconstriction with resulting hypoxaemia. Recent studies have suggested that nitric oxide (NO), a selective pulmonary vasodilator, may be a better screening agent. ${ }^{45}$ The purpose of the present study was to evaluate the ability of NO to predict a response to calcium channel blockers, and to compare its effects on haemodynamics and gas exchange with those of $\mathrm{PGI}_{2}$.

\section{Methods}

Patients were referred after complete cardiopulmonary evaluation with right heart catheterisation indicated the presence of precapillary pulmonary hypertension, defined as a mean pulmonary artery pressure (PAP) exceeding $25 \mathrm{~mm} \mathrm{Hg}$ at rest ${ }^{6}$ without left ventricular failure. The study was approved by the ethics committee of our institution and informed consent was obtained from the patients.

A flow directed pulmonary artery catheter and a radial arterial catheter were inserted. Cardiac output (CO) was determined by the thermodilution method. Arterial and mixed 
Table 1 Individual responses to vasodilating agents

\begin{tabular}{|c|c|c|c|c|c|c|c|c|c|c|c|c|}
\hline Patient no. & $\mathrm{NO}$ & $\begin{array}{l}\text { Dose* } \\
(p p m)\end{array}$ & $\begin{array}{l}\triangle P A P \\
(\%)\end{array}$ & $\begin{array}{l}\triangle P V R \\
(\%)\end{array}$ & $P G I_{2}$ & $\begin{array}{l}\text { Dose* } \\
(\mathrm{ng} / \mathrm{kg} / \mathrm{min})\end{array}$ & $\begin{array}{l}\triangle P A P \\
(\%)\end{array}$ & $\begin{array}{l}\triangle P V R \\
(\%)\end{array}$ & Nifedipine & $\begin{array}{l}\text { Dose* } \\
(m g)\end{array}$ & $\begin{array}{l}\triangle P A P \\
(\%)\end{array}$ & $\begin{array}{l}\triangle P V R \\
(\%)\end{array}$ \\
\hline $\begin{array}{l}1 \\
2 \\
3 \\
4 \\
5 \\
6 \\
7 \\
8 \\
9 \\
10 \\
\text { No of responders } \\
\text { Mean (SD) }\end{array}$ & $\begin{array}{l}+ \\
+ \\
- \\
+ \\
+ \\
+ \\
+ \\
- \\
- \\
- \\
6\end{array}$ & $\begin{array}{l}20 \\
20 \\
40 \\
40 \\
20 \\
40 \\
20 \\
40 \\
40 \\
40 \\
32(10)\end{array}$ & $\begin{array}{l}-22 \\
-41 \\
-11 \\
-22 \\
-23 \\
-7 \\
-21 \\
+2 \\
-2 \\
0 \\
-15(13)\end{array}$ & $\begin{array}{l}-26 \\
-44 \\
-16 \\
-36 \\
+5 \\
-21 \\
-35 \\
-1 \\
+17 \\
0 \\
-16(20)\end{array}$ & $\begin{array}{l}+ \\
+ \\
- \\
+ \\
+ \\
+ \\
+ \\
- \\
- \\
+ \\
+\end{array}$ & $\begin{array}{r}6 \\
6 \\
10 \\
10 \\
10 \\
8 \\
6 \\
10 \\
10 \\
10 \\
9(2)\end{array}$ & $\begin{array}{l}-16 \\
-28 \\
0 \\
-12 \\
-21 \\
-3 \\
-21 \\
+2 \\
+12 \\
-4 \\
-9(12)\end{array}$ & $\begin{array}{l}-50 \\
-61 \\
-10 \\
-42 \\
-20 \\
-20 \\
-54 \\
-17 \\
-8 \\
-38 \\
-32(19)\end{array}$ & $\begin{array}{l}+ \\
+ \\
- \\
+ \\
+ \\
+ \\
+ \\
- \\
- \\
- \\
6\end{array}$ & $\begin{array}{r}50 \\
10 \\
110 \\
10 \\
30 \\
20 \\
30 \\
15 \\
30 \\
30 \\
34(30)\end{array}$ & $\begin{array}{l}-11 \\
-32 \\
+9 \\
-18 \\
-18 \\
-8 \\
-30 \\
+6 \\
+5 \\
-12 \\
-11\end{array}$ & $\begin{array}{l}-34 \\
-53 \\
+22 \\
-38 \\
-24 \\
-35 \\
-39 \\
-0 \\
-6 \\
-13 \\
-22(22)\end{array}$ \\
\hline
\end{tabular}

$\mathrm{PGI}_{2}=$ prostacyclin; $\triangle \mathrm{PAP}$ and $\Delta \mathrm{PVR}=$ change in mean pulmonary artery pressure and pulmonary vascular resistance induced by the agent; $+=$ responder; $-=$ non-responder.

* Dose required to obtain a significant effect in responders and maximal administered dose in non-responders. For definition of response, see text.

venous blood samples were collected simultaneously for blood gas determinations. Derived variables were computed according to standard equations.

Since a previous study from our ICU demonstrated a 24 hour variability of $11 \%$ in mean $\mathrm{PAP}$ and $14 \%$ in pulmonary vascular resistance (PVR) in patients with pulmonary hypertension, in the absence of any drug administration, ${ }^{7}$ these parameters were first recorded every hour for 24 hours without any pharmacological intervention. The mean 24 hour variability was defined as the coefficient of variation of these measurements. NO was administered at inhaled concentrations of 10 , 20 , and $40 \mathrm{ppm}$, each for 15 minutes, using a previously described technique. ${ }^{8}$ Inhaled NO and $\mathrm{NO}_{2}$ concentrations were monitored online by an electrochemical device (Polytron, Dräger AG, Lubeck, Germany). After a one hour period to allow a return to baseline conditions, a continuous infusion of prostacyclin $\left(\mathrm{PGI}_{2}\right.$, Flolan, Wellcome Research Laboratory, Beckenham, UK) was started at an initial rate of $1 \mathrm{ng} / \mathrm{kg} / \mathrm{min}$, and increased by $1 \mathrm{ng} / \mathrm{kg} / \mathrm{min}$ increments every 10 minutes up to a maximum of $10 \mathrm{ng} / \mathrm{kg} / \mathrm{min}$. Measurements were made when a response was obtained, side effects appeared, or if there was no response after 10 minutes at the maximum dosage. The following day patients received a loading dose of $10 \mathrm{mg}$ nifedipine orally followed by $20 \mathrm{mg}$ every hour. If the mean systemic arterial pressure was $75 \mathrm{~mm} \mathrm{Hg}$ or less the loading dose was reduced to $5 \mathrm{mg}$ and subsequent doses to $10 \mathrm{mg}$.

Response to any vasodilator was considered positive if the mean PAP and/or PVR decreased by $20 \%$ or more. ${ }^{9}$ Side effects prompting interruption of drug administration included subjective intolerance, a decrease in the mean systemic arterial pressure to $\leq 60 \mathrm{~mm} \mathrm{Hg}$, or a lowering of arterial saturation $\left(\mathrm{SaO}_{2}\right)$ to $<90 \%$.

Comparisons between baseline measurements and those obtained with each agent were performed using a paired $t$ test. A paired $t$ test was used to compare baseline values before each vasodilator. The response to each vasodilator was compared with the spontaneous variability in the following manner: for each patient the difference between the highest and lowest mean PAP values obtained during the 24 hour measurement represents the maximum possible decrease in mean PAP ( $\triangle \mathrm{PAPspont)}$ resulting from spontaneous variability. The val- ues of $\triangle$ PAPspont for the responders were compared with those of the decrease in mean PAP obtained with each vasodilator using a Wilcoxon signed rank test.

\section{Results}

All results are expressed as mean (SD). Ten patients were studied, four of whom had primary pulmonary hypertension while in the others pulmonary hypertension was associated with cirrhosis and portal hypertension (2), connective tissue disease (2), thromboembolic disease (1), and HIV infection (1). All had severe pulmonary hypertension (mean PAP 49 (13) mm Hg, PVR 974 (573) dyn.s.cm ${ }^{-5}$ ), and eight had a low cardiac index $\left(1.9(0.5) \mathrm{l} / \mathrm{min} / \mathrm{m}^{2}\right)$ and increased systemic vascular resistance (SVR) (2227 (852) dyn.s.cm ${ }^{-5}$ ). The mean 24 hour variability in the mean PAP and PVR was 11 (3) $\%$ and $13(5) \%$, respectively. All patients except patient 1 were moderately hypoxaemic $\left(\mathrm{PaO}_{2} 8.9(1.2) \mathrm{kPa}\right)$ and had increased Qva/ QT (18 (8)\%). Three patients (nos 4, 6, and 8 ) were receiving supplemental oxygen.

There was no difference between baseline values before administration of the three agents, except for a small but significant difference in heart rate between $\mathrm{NO}$ and $\mathrm{PGI}_{2}$ (80 (13) beats/min before NO and 73 (9) beats/min before $\mathrm{PGI}_{2}$ ). The individual responses to the three vasodilators are indicated in table 1 , together with the dose of the agent required to obtain that effect. Six patients responded to all three agents $(60 \%)$ while three responded to none $(30 \%)$. Patient 10 responded to $\mathrm{PGI}_{2}$ only.

All results hereafter refer to the group of 10 patients, and the values obtained with each vasodilator are compared with baseline values documented prior to testing with that particular vasodilator. Mean PAP was lowered by NO (41 (10) versus 49 (12) $\mathrm{mm} \mathrm{Hg}, \mathrm{p}<0.01)$ and nifedipine (42 (15) versus 48 (14) $\mathrm{mm} \mathrm{Hg}$, $\mathrm{p}<0.04)$. PVR decreased with NO (798 (460) versus 974 (563) dyn.s.cm $\left.{ }^{-5}, \mathrm{p}<0.01\right)$ and nifedipine (757 (376) versus 1008 (570) dyn.s.cm $\left.{ }^{-5}, \mathrm{p}<0.01\right) . \mathrm{PGI}_{2}$ decreased only the PVR (650 (366) versus 948 (435) dyn.s. $\mathrm{cm}^{-5}$, $\mathrm{p}<0.003)$. Heart rate was decreased by $\mathrm{NO}$ (74 (10) versus 80 (13) beats/min, $\mathrm{p}<0.05)$, increased by $\mathrm{PGI}_{2}$ (84 (9) versus 73 (9) beats/ $\min , \mathrm{p}<0.001)$, and unaltered by nifedipine. $\mathrm{PGI}_{2}$ increased the cardiac index (3.2 (1.4) 


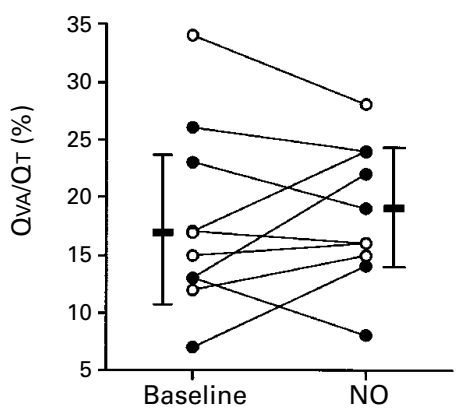

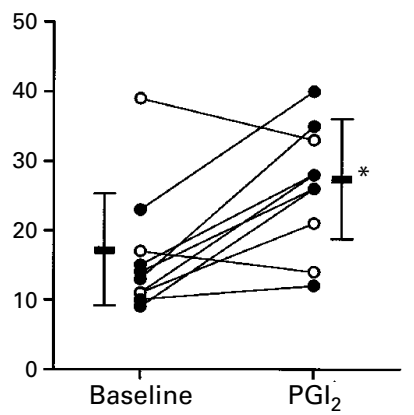

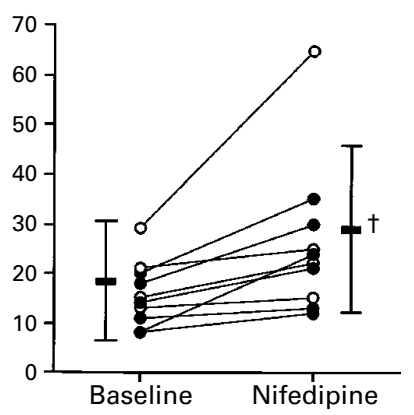

Figure 1 Effect of $(A)$ nitric oxide (NO), (B) prostacyclin $\left(P G I_{2}\right)$, and $(C)$ nifedipine on venous admixture $(Q v A / Q T)$ in responders (O) and non-responders (O) showing individual responses and mean (SD). ${ }^{*} p<0.01 ; \dagger p<0.02$ versus baseline values.

versus $\left.2.2(0.9) 1 / \mathrm{min} / \mathrm{m}^{2}, \mathrm{p}<0.002\right)$. Mean SAP was decreased by $\mathrm{PGI}_{2}(72$ (14) versus 89 (19) $\mathrm{mm} \mathrm{Hg}, \mathrm{p}<0.001)$ and nifedipine $(72$ (15) versus $86(17) \mathrm{mm} \mathrm{Hg}, \mathrm{p}<0.003)$. SVR was decreased by $\mathrm{PGI}_{2}(1052$ (390) versus 1887 (737) dyn.s.cm $\left.{ }^{-5}, \mathrm{p}<0.001\right)$ and nifedipine (1331 (604) versus 1860 (750) dyn.s.cm ${ }^{-5}$, $\mathrm{p}<0.002) . \mathrm{PaO}_{2}$ was lowered by $\mathrm{PGI}_{2}$ (8.7 (1.4) versus 10.8 (1) $\mathrm{kPa}, \mathrm{p}<0.01)$ and nifedipine (8.6 (1.4) versus $10.2(1.5) \mathrm{kPa}, \mathrm{p}<0.01)$. Qva/ QT was markedly increased with $\mathrm{PGI}_{2}$ and nifedipine in all patients, whereas with $\mathrm{NO}$ there was no significant variation for the group, even though Qva/QT did increase in three patients (fig 1).

In responders the decrease in mean PAP with each vasodilator was significantly different from spontaneous variability ( $\triangle$ PAPspont $12(5) \%$ versus $23(10) \%$ with NO, 17 (7)\% with $\mathrm{PGI}_{2}$, and $20(9) \%$ with nifedipine, $\mathrm{p}<0.05)$.

NO inhalation was well tolerated in all patients. With $\mathrm{PGI}_{2}$ patients 3 (non-responder), 4 and 6 (responders) complained of moderate chest tightness, slight throbbing headache, and a flushing sensation. Nifedipine induced hypotension with nausea and lightheadedness in patients 1 (responder), 3 and 9 (nonresponders), and hypoxaemia in patients 8 and 9 (non-responders).

\section{Discussion}

This study confirms that NO inhalation can accurately predict the response to nifedipine without adverse consequences. In contrast, $\mathrm{PGI}_{2}$ induced a substantial lowering of SVR and SAP, accompanied by a rise in cardiac index and heart rate as well as an absence of decrease in PAP and a marked increase in Qva/ QT.

These results confirm those of recent studies by Sitbon et $a l^{4}$ and Cockrill et $a l{ }^{5}$ with the exception that the overall response rate of $60 \%$ to vasodilators is higher than the rates of $37 \%$ and $50 \%$ obtained in these studies. The drug dosage used in our study is consistent with the standardised protocols used in most studies. ${ }^{14}$ The higher response rate may be explained by a number of factors. Firstly, the non-homogeneous nature of our study group must be considered. Our patients all had precapillary pulmonary hypertension but only four (nos 2 and 9) had primary pulmonary hypertension as defined by the National Institute of Health Patients Registry for the Characterisation of Primary Pulmonary Hypertension. ${ }^{6}$ However, over the years it has become apparent that conditions such as hepatic cirrhosis, collagen disease, and HIV infection, which were present in some of our patients, are often closely associated with primary pulmonary hypertension. ${ }^{10}$ Secondly, the criteria we chose as a positive response to a given vasodilator were decreases of $20 \%$ or more in mean PAP or PVR, in line with a study by Weir et al. ${ }^{9}$ Other studies have relied on different response criteria such as a reduction in PVR of $50 \%$ and of mean PAP by $33 \%,{ }^{11} \mathrm{a} \geq 20 \%$ decrease in mean PAP and PVR, ${ }^{1}$ or a $30 \%$ decrease in total pulmonary resistance. ${ }^{4}$ Thirdly, the duration of pulmonary hypertension before testing might have an influence on reversibility. However, this factor is difficult to account for as information on the time from onset of pulmonary hypertension in these patients was not available.

$\mathrm{PGI}_{2}$ caused a substantial reduction in SVR which was accompanied by a lowering of SAP and a rise in heart rate and cardiac index, effects consistent with the known properties of the drug. ${ }^{12}$ While NO had no effect on gas exchange, $\mathrm{PGI}_{2}$ produced a considerable increase in Qva/QT (fig 1), as well as a concomitant fall in $\mathrm{PaO}_{2}$. This could result from increased blood flow to low ventilation-perfusion pulmonary zones by attenuating hypoxic vasoconstriction ${ }^{13}$ or a rise in cardiac index. ${ }^{14}$ Finally, $\mathrm{PGI}_{2}$ and nifedipine had comparable effects on haemodynamics and gas exchange.

In conclusion, this study supports the existing preliminary data that, with a predictive ability at least as good or perhaps better than $\mathrm{PGI}_{2}, \mathrm{NO}$ could be a valid alternative to $\mathrm{PGI}_{2}$ in testing for preserved pulmonary vasoreactivity in patients with severe precapillary pulmonary hypertension.

1 Rich S, Kaufmann E, Levy PS. The effect of high doses of calcium-channel blockers on survival in primary pulmonary hypertension. $N$ Engl f Med 1992;327:76-81.

2 Partanen J, Nieminen M, Luomanmäki K. Death in a patien with primary pulmonary hypertension after $20 \mathrm{mg}$ of nifedipine. N Engl f Med 1993;329:812.

3 Palevsky HI, Long W, Crow J, Fishman AP. Prostacyclin and acetylcholine as screening agents for acute pulmonary 
vasodilator responsiveness in primary pulmonary hypertension. Circulation 1990;82:2018-26.

4 Sitbon O, Brenot F, Denjean A, Bergeron A, Parent F, Azarian $\mathrm{R}$, et al. Inhaled nitric oxide as a screening vasodilator agent in primary pulmonary hypertension. $A m \mathcal{F}$ Respir Crit Care Med 1995;151:384-9.

5 Cockrill BA, Kackmarek R, Thompson BT, Zapol WA, Semigran MJ. Response to inhaled nitric oxide identifies a subset of patients with pulmonary hypertension likely a subset of patients with pulmonary hypertension likely
to respond to high dose calcium channel antagonists. $\mathrm{Am}$ to respond to high dose calcium chann

J Respir Crit Care Med 1995;151:A728.
6 Rich S, Dantzker DR, Ayres SM, Bergofsky EH, Brundage $\mathrm{BH}$, et al. Primary pulmonary hypertension: a national prospective study. Ann Intern Med 1987;107:216-23.

7 Chevrolet JC, Schmid F. "Spontaneous" variability of pulmonary haemodynamics during vasodilator tests in pulmonary precapillary hypertension. Eur f Intern Med 1992; monary prece

8 Jolliet P, Thorens JB, Chevrolet JC. Pulmonary vascular reactivity in severe pulmonary hypertension associated with mixed connective tissue disease. Thorax 1995;50: 96-7

9 Weir EK, Rubin LJ, Ayres SM, Bergofsky EH, Brundage $\mathrm{BH}$, Detre KM, et al. The acute administration of vasodilators in primary pulmonary hypertension. Am Rev Respir Dis 1989;140:1623-30.

10 Fishman AP. The National Registry on Primary Pulmonary Hypertension. Eur Respir Rev 1995;5:259-63.

11 Rich S, Brundage B. High-dose calcium channel-blocking therapy for primary pulmonary hypertension: evidence for long-term reduction in pulmonary arterial pressure and regression of right ventricular hypertrophy. Circulation 1987;76:135-41.

12 Jones DK, Higenbottam TW, Wallwork J. Treatment of primary pulmonary hypertension with intravenous epoprostenol. Br Heart $\mathcal{F}$ 1987;57:270-8.

13 Sprague RS, Stephenson AH, Lonigro AJ. Prostaglandin I supports blood flow to hypoxic alveoli in anesthetized dogs. F Appl Physiol 1984;56:1246-51.

14 Lynch JP, Myhre JG, Dantzker DR. Influence of cardiac output on intrapulmonary shunt. $\mathcal{F}$ Appl Physiol 1979;46 315-21.

\title{
Cellular profiles in asthmatic airways: a comparison of induced sputum, bronchial washings, and bronchoalveolar lavage fluid
}

\author{
V M Keatings, D J Evans, B J O’Connor, P J Barnes
}

National Heart and Lung Institute, Dovehouse Street, London SW3 6LY, UK

V M Keatings

D J Evans

B J O'Connor

P J Barnes

Correspondence to: Dr V M Keatings, Education and Research Centre, St Vincent's Hospital, Dublin 4, Ireland.

Received 28 July 1995

Returned to authors

9 October 1995

Revised version received

6 November 1996

Accepted for publication

18 November 1996

\begin{abstract}
Background - Analysis of bronchoalveolar lavage fluid has improved our understanding of the pathogenesis of asthma. Safety issues and access to expert resources limit this technique as a research tool. Induced sputum is a non-invasive method of collecting airway fluid which is applicable to subjects with a range of severity of airflow obstruction. The method of sputum collection and processing differs between groups. A study was undertaken to compare induced sputum with bronchoscopically collected fluid.

Methods - Sixteen patients with mild stable asthma underwent both sputum induction and bronchoscopic examination with bronchial washings and bronchoalveolar lavage (BAL) in random order, with each procedure being separated by an interval of 12 days. Airway fluid was processed and stained for differential cell counting.

Results - Induced sputum was relatively rich in neutrophils and eosinophils compared with bronchial washings and BAL fluid (mean (SE) $1.3(0.4) \%, 5.0(2.7) \%$, and $36.4(3.7) \%$ neutrophils and $0.6(0.1) \%$, $1.6(0.6) \%$, and $3.3(1.1) \%$ eosinophils in BAL fluid, bronchial washings, and induced sputum, respectively). The proportions of cells obtained at sputum induction correlated with those in bronchial washings but not BAL fluid $(r=0.6$ and 0.7 for neutrophils and eosinophils, respectively, $p<0.05)$. By contrast, induced
\end{abstract}

sputum had a lower proportion of lymphocytes and macrophages than bronchial washings or BAL fluid, without any correlation.

Conclusion - Induced sputum is rich in neutrophils and eosinophils and poor in lymphocytes, suggesting an origin in the larger airways. Induced sputum adequately reflects the findings in fluid collected by direct bronchoscopy.

(Thorax 1997;52:372-374)

Keywords: induced sputum, bronchial washings, differential cell counts.

Airway inflammation is a characteristic feature of asthma. The use of bronchoalveolar lavage (BAL) and bronchial biopsy has provided a greater understanding of the pathogenesis of this disease. ${ }^{1}$ The application of these techniques has helped to define, not only the inflammatory cell population, but also the presence of inflammatory mediators and cytokines under basal and challenge conditions. ${ }^{2}$

Collection of BAL fluid is, however, an invasive procedure with a consequent associated morbidity. For research purposes bronchoscopy is restricted to patients with mild airflow obstruction and must be performed by experienced investigators. Furthermore, there is a limit to the number of times the procedure can be undertaken and, due to the invasive nature of this procedure, it may be difficult to recruit volunteers for studies involving bronchoscopy.

Induced sputum is used to obtain airway derived fluid for diagnostic ${ }^{3}$ and research 
purposes. ${ }^{45}$ We have shown the method to be safe and reproducible over a two week period. ${ }^{6}$ The aim of this study was to determine whether the inflammatory cell population obtained from induced sputum correlates with that from bronchial washings and BAL fluid in asthma. Fahy et al have compared induced sputum and bronchial washing in terms of differential cell counts and have found these to correlate. ${ }^{7}$ We report the findings of a similar study using a modified method of sputum collection and processing.

\section{Methods}

SUBJECTS

Sixteen subjects (12 men) with stable asthma, of mean (SE) age 25.3 (3.1) years and forced expiratory volume in one second $\left(\mathrm{FEV}_{1}\right) 95.6$ (4.1)\% predicted, were recruited. All were taking inhaled $\beta_{2}$ agonists only and subjects who had a respiratory tract infection or exacerbation of asthma within the previous eight weeks were excluded. All subjects gave written informed consent and the study was approved by the ethics committee of the Royal Brompton Hospital.

STUDY DESIGN

Each subject underwent a bronchoscopic examination and a sputum induction in random order with an interval of 12 days between each procedure.

Sputum induction and processing

Subjects inhaled $200 \mu \mathrm{g}$ salbutamol via a metered dose inhaler 10 minutes before the sputum induction. Each subject mouthwashed thoroughly with water before inhaling 3.5\% saline nebulised via an ultrasonic nebuliser (DeVilbiss 99, Heston, UK) for a mean duration of 15 (6) minutes. Subjects were encouraged to cough deeply after five minutes and at three minute intervals thereafter. The sputum induction was terminated when at least $1 \mathrm{ml}$ of sputum had been collected; the mean duration of the procedure was 25 minutes. Sputum was coughed into a polypropylene pot and all saliva was discarded separately.

The volumes of the samples were recorded. The sample was diluted with $2 \mathrm{ml}$ Hank's balanced salt solution (HBSS) containing $1 \%$ dithiothreitol (DTT) (Sigma Chemicals, Poole, UK) and gently vortexed at room temperature. When homogeneous, samples were further diluted with HBSS and centrifuged at $300 \mathrm{~g}$ for 10 minutes and the cell pellet was resuspended. Total cell counting was carried out on a haemacytometer using Kimura stain and slides were made using a cytospin (Shandon, Runcorn, UK) and stained with May-Grunwald-Giemsa stain for differential cell counts which were carried out by a blinded observer. Differential cell counts were expressed as percentage of immunocompetent cells - that is, excluding squamous epithelial cells.
Table 1 (Mean (SE) differential cell counts in bronchoalveolar lavage (BAL) fluid, bronchial washings bronchoalveolar lavage (BAL) fuid,
and induced sputum from 14 subjects

\begin{tabular}{lrrr}
\hline & BAL fluid & $\begin{array}{l}\text { Bronchial } \\
\text { washings }\end{array}$ & \multicolumn{1}{c}{$\begin{array}{l}\text { Induced } \\
\text { sputum }\end{array}$} \\
\hline Macrophages & $88.0(3.6)$ & $85.5(3.4)$ & $59.9(4.2)$ \\
Neutrophils & $1.3(0.4)$ & $5.0(2.7)$ & $36.4(3.7)$ \\
Eosinophils & $0.6(0.1)$ & $1.6(0.6)$ & $3.3(1.1)$ \\
Lymphocytes & $11.8(3.5)$ & $6.2(1.9)$ & $0.3(0.2)$ \\
\hline
\end{tabular}

Bronchoscopic examination

Each subject inhaled $200 \mu \mathrm{g}$ salbutamol 30 minutes before the bronchoscopic examination. The bronchoscope (Key Med Ltd, Southend, Essex) was introduced via the nose following application of the local anaesthetic lignocaine $4 \%$ and sedation with intravenous midazolam in a dose of $5-10 \mathrm{mg}$. The bronchoscope was wedged in the right middle lobe, $60 \mathrm{ml}$ of warmed normal saline was instilled, and the aspirate was collected and labelled as bronchial washing. The next $180 \mathrm{ml}$ saline was instilled and the aspirated fluid labelled as BAL fluid.

Processing of bronchial washing and BAL fluid samples

Bronchial washing and BAL samples were kept on ice prior to processing. They were centrifuged at $300 \mathrm{~g}$ for 10 minutes, the pellet was resuspended in Hank's balanced salt solution, and a total cell count was carried out on a haemacytometer. Slide preparations were made using a cytospin and stained as for the induced sputum slides.

\section{STATISTICAL ANALYSIS}

Total and differential cell counts were compared using Pearson's rank correlation coefficient. A p value of $<0.05$ was considered significant.

\section{Results}

All subjects produced an adequate specimen of sputum (defined as at least $1 \mathrm{ml}$ of sputum with $<50 \%$ squamous epithelial cells on differential cell counting). Nine subjects underwent bronchoscopic examination before sputum induction. Two of these were withdrawn from the study as they developed a cough productive of sputum following bronchoscopy. $\mathrm{FEV}_{1}$ was $3.82(0.20) 1,4.14(0.21) 1$, and $3.84(0.26) 1$ at baseline, following salbutamol, and following sputum induction, respectively.

DIFFERENTIAL CELL COUNTS

The differential cell counts are shown in table 1. There was a significant correlation between the proportions of neutrophils and eosinophils in induced sputum and bronchial washings $(r=$ 0.6 and 0.7 for neutrophils and eosinophils, respectively, $\mathrm{p}<0.05$; fig 1 ). The relationship between cell profiles in induced sputum and BAL fluid was not, however, significant. 

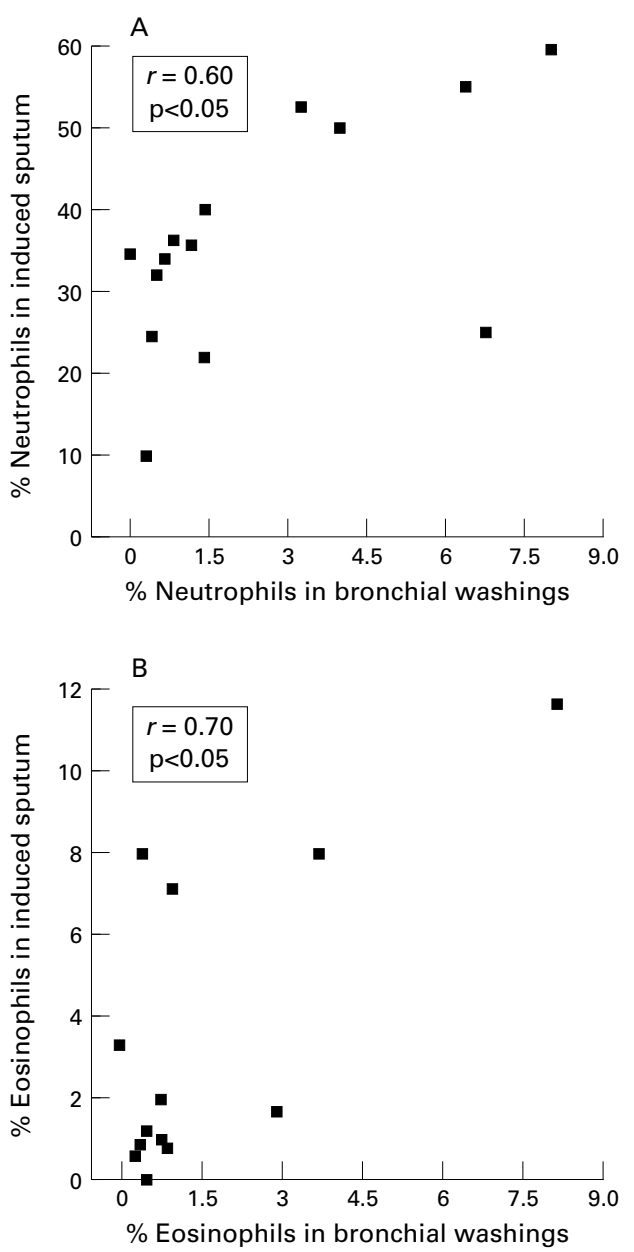

Figure 1 Correlation between percentage of $(A)$ neutrophils and (B) eosinophils in induced sputum and bronchial washings. $r=$ Pearson's rank correlation coefficient.

\section{Discussion}

We have confirmed that sputum induction allows sampling of fluid in which the proportions of eosinophils and neutrophils correlate with bronchial washings and is likely to have originated in the airways. The proportions of cells in induced sputum, however, did not correlate with BAL fluid, possibly because a different generation of airway is being sampled. Previous data have shown that there are more pronounced changes in eosinophils in bronchial washings than in BAL fluid after allergen challenge, suggesting that bronchial washing samples the site of asthmatic inflammation. ${ }^{8}$ Our observation that eosinophil proportions from induced sputum correlate with those from bronchial washings suggests that induced sputum is a suitable tool with which to detect asthmatic inflammation of the bronchial lumen.

Induced sputum is richer in eosinophils and neutrophils and poorer in lymphocytes and macrophages than bronchial washings or BAL fluid. The proportions of neutrophils and eosinophils decreased whereas the proportions of lymphocytes and macrophages increased progressively from induced sputum to bronchial washing and BAL fluid. It has previously been shown that neutrophils and eosinophils are increased whilst macrophages and lymphocytes are reduced in bronchial washings compared with BAL fluid. ${ }^{9}$ The finding of high percentages of neutrophils and eosinophils in induced sputum suggests that this fluid originates in the more proximal bronchi or may be a result of the relative ease by which different cell types are cleared using lavage and sputum induction. Alternatively, these findings could be a response to hypertonic saline inhalation. This is unlikely as differential cell counts in induced sputum do not differ from those in spontaneously produced sputum. ${ }^{10}$

Sputum induction is a non-invasive technique that was tolerated well by all the subjects and there were no adverse effects. As sputum induction is a simple inexpensive procedure we consider that it could be used as a routine tool in clinical studies of asthma, allowing information on the anti-inflammatory effects of drugs to be assessed and the course of inflammatory disease in the airways and the effects of intervention to be monitored. Its simple non-invasive nature may facilitate recruitment into such studies.

1 Smith DL, Deshazo RD. Bronchoalveolar lavage in asthma an update and perspective. Am Rev Respir Dis 1993;148: 523-32.

2 De Monchy JGR, Kauffman HF, Venge, et al. Bronchoalveolar lavage eosinophils during allergen induced late asthmatic responses. Am Rev Respir Dis 1985;131:373-6.

3 Leigh TR, Parsons P, Hume C, Hussain OAN, Gazzard B, Collins JV. Sputum induction for dian OAN, Gazzard B, carinii pneumonia. Lancet 1989;ii:205-6.

4 Pin I, Gibson PG, Kolendowicz R, Girgis-Gabardo A, Denburg JA, Hargreave FE, et al. Use of induced sputum to investigate airway inflammation in asthma. Thorax 1992; investigate

5 Fahy JV, Liu J, Wong H, Boushey H. Cellular and biochemical analysis of induced sputum from asthmatic an healthy subjects. Am Rev Respir Dis 1993;147:1126-31.

6 Keatings VM, Collins PD, Scott DM, Barnes PJ. Difference in interleukin-8 and tumour necrosis factor- $\alpha$ in induced sputum from patients with chronic obstructive pulmonary disease and asthma. Am $\mathcal{F}$ Respir Crit Care Med 1996;153 $530-4$

7 Fahy JV, Wong H, Liu J, Boushey HA. Comparison of samples collected by sputum induction and bronchoscopy from asthmatic and healthy subjects. Am 7 Respir Crit Car Med 1995;152:53-8.

8 Aalbers R, Kauffman HF, Vrugt B, Smith M, Koëter GH, Timens W, et al. Allergen induced recruitment of inflammatory cells in lavage 3 and 24 hours after challenge in allergic asthmatic lungs. Chest 1993;103:1178-84.

9 Martin TR, Raghu G, Maunder R, Springmeyer S. The effects of chronic bronchitis and chronic airflow limitation on lung cell populations recovered by bronchoalveolar lavage. Am Rev Respir Dis 1985;132:254-60.

10 Byrnes CA, Bush A, Barnes PJ. A comparison between the cellular and cytokine profile of spontaneous and induced sputum in children with cystic fibrosis. Am $\mathcal{F}$ Respir Crit Care Med 1995;151:A704. 